\title{
Risk factors for ST- Elevation Myocardial Infarction in a tertiary hospital in central Nepal
}

\author{
Sachin Dhungel, Shankar Laudari, Laxman Dubey, Rajesh Panjiyar, Hari Upadhyay, G \\ Subramanyam
}

Department of Cardiology, College of Medical Sciences, Bharatpur, Nepal

Correspondence
Dr. Sachin Dhungel
Department of Cardiology,
College of Medical Sciences,
Bharatpur, Nepal
Email:
dr_dhungel@hotmail.com
DOI: http://dx.doi.org/10.3126/
jcmsn.v13i4.18615

Orcid ID: orcid.org/0000-0002 $-4493-3203$

Article received: Nov $15^{\text {th }} 2017$ Article accepted: Dec $18^{\text {th }} 2017$

\begin{abstract}
Background \& Objectives: Coronary artery disease is the common cardiac disease in Nepal. The objective of the study is to explore different risk factors for coronary artery disease. Materials \& Methods: This was cross sectional hospital based study studying the baseline clinical and angiographic characters in ST Myocardial infarction who had Primary Percutaneous coronary intervention (PPCI) in College of Medical Science Teaching Hospital (CMSTH). Results: There were 95 cases with male $77(82.1 \%)$ and female $18(17.9 \%)$. The mean age overall was $60.05 \pm 12.2$. The mean age of male was $59.9 \pm 12.5$ and of female was $60.5 \pm 11.2$ years. Apart from chest pain, common clinical symptoms were sweating in $60(63.2 \%)$ cases, dyspnea in $41(43.2 \%)$, nausea/ vomiting in $38(40 \%)$, dizziness in $17(17.9 \%)$ and epigastric pain in nine $(9.5 \%)$ cases. Common risk factors were smoking in $83(87.7 \%)$ cases, hypertension 59 in $(51.6 \%)$, diabetes in $24(25.3 \%)$, dyslipidemia in 24 $(25.3 \%)$ and family history in six $(6.3 \%)$ cases. Common angiographic variables were single vessel disease (SVD) in $45(47.4 \%)$, double vessel disease (DVD) in $20(21.1 \%)$ and triple vessel disease (TVD) in 30 $(31.6 \%)$ cases. Infarct related artery were Right coronary artery (RCA) in $43(45.3 \%)$, Left circumflex artery (LCx) in seven (7.4\%) and Left anterior descending artery (LAD) in $45(47.4 \%)$ cases. Conclusion: Patients visiting CMSTH had classical symptoms and risk factors of myocardial infarction. Single vessel disease and Left anterior descending infarction was the most common vessel involved.
\end{abstract}

Key words: Coronary artery disease; risk factors; myocardial infarction

Citation: Dhungel S, Laudari S, Dubey L, Panjiyar R, Upadhyay H, Subramanyam G. Risk factors for STElevation Myocardial Infarction in a tertiary hospital in central Nepal. JCMS Nepal. 2017;13(4):416-9.

\section{INTRODUCTION}

Coronary artery disease is the common heart disease in Nepal with prevalence of four percent. ${ }^{1,2}$ College of Medical Sciences Teaching Hospital (CMSTH) is the medical college located in Chitwan with the first few cath lab established outside valley. ${ }^{3}$ It provides cardiac interventional services to rural areas like Chitwan, Nawalparasi, Makuwanpur, Tanahun, Gorkha, Rupendehi, Parsa and nearby hilly and terai districts.

Primary PCI has been the first recommended modality for treatment of Coronary artery diesease. ${ }^{4}$ Various risk factors have been described in patients with Myocardial infarction-mainly for male, middle aged, smoking, diabetes, dyslipidemia and family history. Through coronary angiography, the infarct related artery can be identified and depending upon the lesion in other vessels, the classification into single, double and triple vessel disease can be defined.

The study aims to identify different presenting complains and risk factors among the patients visiting the cardiology department of College of Medical Sciences and Teaching Hospital, Bharatpur.

\section{MATERIALS AND METHODS}

This cross sectional hospital based descriptive study was conducted in College of Medical Science, 
Bharatpur. Patients with chest pain and ST elevation who underwent Primary Percutaneous Coronary Intervention ( Primary PCI) were studied for two years duration (2013 to 2015AD). Elective PCI, Rescue PCI and PCI for Non-ST elevation Myocardial Infarction were excluded. The study was approved by the institutional review committee of the institution. Baseline characteristics were recorded according to profoma. Continuous values were expressed as means and standard deviation and categorical values were expressed in frequency and percentages. Chi square test was used for analyzing categorical values. $\mathrm{P}<0.05$ was considered statistically significant. Data had been tabulated and analyzed in Microsoft Excel and SPSS version 20 .

\section{RESULTS}

There were 95 cases with male $77(82.1 \%)$ and female $18(17.9 \%)$. The mean age was $60.05 \pm 12.2$ years. The mean age of males was $59.9 \pm 12.5$ and female $60.5 \pm 11.2$ years. Mean age for the single vessel disease (SVD) was $59.4 \pm 11.5$ years, double vessel disease (DVD) $60.2 \pm 9.7$ years and Triple vessel disease (TVD) $59.6 \pm 12.8$ years. The baseline clinical symptoms and distribution of the

Table 1. Baseline clinical characteristics and risk factors.

\begin{tabular}{llll} 
Symptoms & $\mathrm{n}(\%)$ & Risk factors & $\mathrm{n}(\%)$ \\
Sweating & $60(63.2)$ & Smoking & $83(87.4)$ \\
Dyspnea & $41(43.2)$ & Hypertension & $59(51.6)$ \\
$\begin{array}{l}\text { Nausea/ } \\
\text { Vomiting }\end{array}$ & $38(40)$ & Diabetes & $24(25.3)$ \\
$\begin{array}{l}\text { Dizziness } \\
\text { Epigastric } \\
\text { pain }\end{array}$ & $9(9.5 \%)$ & $\begin{array}{l}\text { Family } \\
\text { history }\end{array}$ & $6(6.3)$ \\
\hline
\end{tabular}

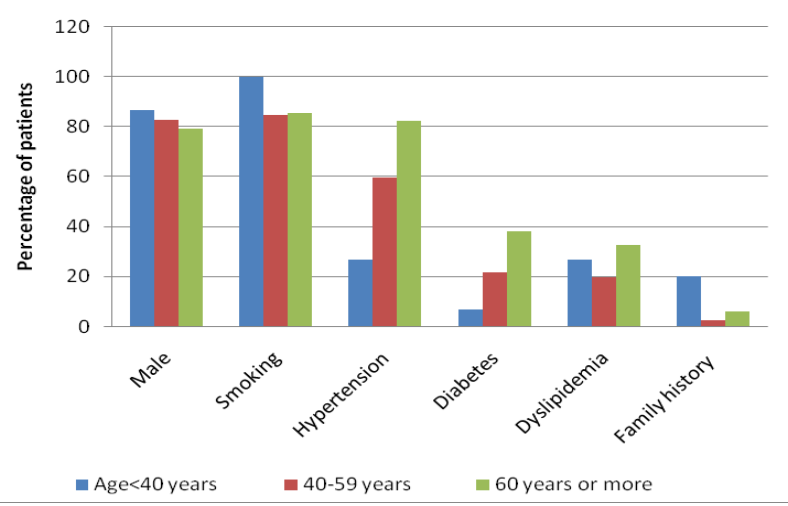

Figure 1.Risk factors distribution according to age categories. risk factors are described in Table 1. The distribution of risk factors according to different age categories is illustrated in Figure 1. Between different age categories, statistical significant difference was noted in presence of hypertension $(p=0.001)$ and diabetes $(p=0.048)$. No statistical significances existed between male gender $(\mathrm{p}=0.824)$, smoking $(\mathrm{p}=0.275)$ and dyslipidemia $(p=0.402)$ among different age categories. The baseline angiographic findings are illustrated in Table 2. The distribution of baseline angiographic findings according to age categories is shown in Figure 2. Statistically significant differences occurred in number of vessels involved $(=0.036)$ but not for the type of infracted vessels $(\mathrm{p}=0.648)$. Between gender, no statistical significance was noted regarding age categories $(\mathrm{p}=0.545)$, smoking $(\mathrm{p}=0.497), \quad$ hypertension $(\mathrm{p}=0.432)$, diabetes $(p=0.161)$, dyslipidemia $(p=0.161)$, number of

Table 2.Baseline Angiographic findings.

\begin{tabular}{|c|c|c|c|}
\hline $\begin{array}{l}\text { No } \\
\text { vessels }\end{array}$ & n (\%) & $\begin{array}{l}\text { Infarct } \\
\text { vessels }\end{array}$ & n (\%) \\
\hline Single & & Right & \\
\hline $\begin{array}{l}\text { vessel } \\
\text { disease } \\
\text { (SVD) }\end{array}$ & 45 & $\begin{array}{l}\text { Coronary } \\
\text { artery }\end{array}$ & \\
\hline Double & & & \\
\hline $\begin{array}{l}\text { vessel } \\
\text { disease }\end{array}$ & & Left & \\
\hline $\begin{array}{l}\text { disease } \\
\text { (DVD) }\end{array}$ & $\begin{array}{l}20 \\
(211)\end{array}$ & $\begin{array}{l}\text { Cirumflex } \\
\text { artery (LCx) }\end{array}$ & \\
\hline $\begin{array}{l}\text { Triple vessel } \\
\text { disease } \\
\text { (TVD) }\end{array}$ & $\begin{array}{l}30 \\
(31.6)\end{array}$ & $\begin{array}{l}\text { Left anterior } \\
\text { descending } \\
\text { artery } \\
\text { (LAD) }\end{array}$ & $45(47.4)$ \\
\hline
\end{tabular}

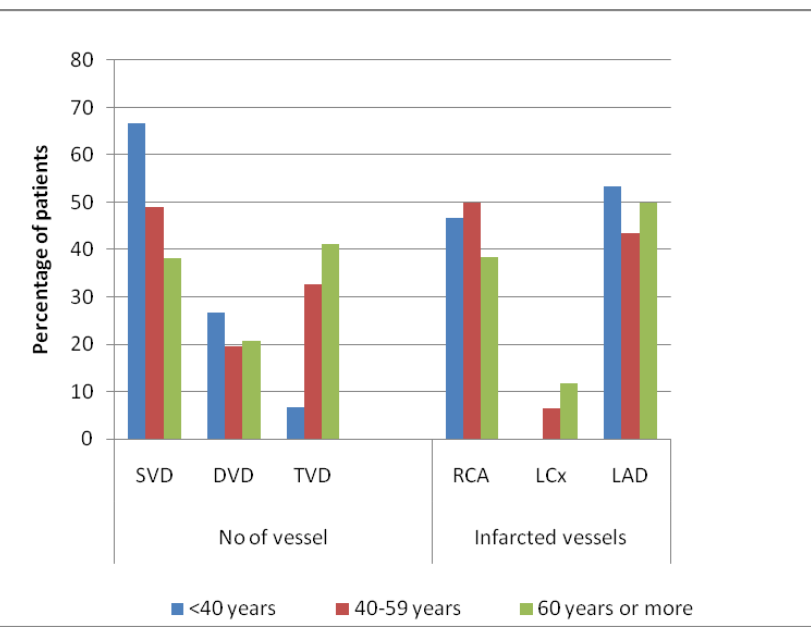

Figure 2. Angiographic baseline characteristics as per the age categories.SVD Single vessel disease DVD Double vessel disease, TVD Triple vessel disease; RCA Right coronary artery LCx Left ciricumflex LAD Left anterior descending 
vessel involved $(\mathrm{p}=0.347)$ and infarct related vessel $(\mathrm{p}=0.855)$.

\section{DISCUSSION}

Different studies of coronary artery disease have been published from Nepal. The mean age in our study was similar to Poudel et $\mathrm{al}^{5}(64 \pm 10.8$ years), Gautam et $\mathrm{al}^{6}$ (64.54 \pm 13.8 years), Dubey et $\mathrm{al}^{3}$ $\left(56.31 \pm 11.4\right.$ years) and Simkhada et $\mathrm{al}^{7}$ $(59.5 \pm 11.01$ years $)$

The male dominance in coronary artery disease was described by Poudel ${ }^{5}$ (62\%), Gautam ${ }^{6}$ (63.1\%), Simkhada $^{7}(72 \%)$ and Tamrakar $^{8}(74 \%)$. Females were elderly, hypertensive and dyslipidemic and less smokers compared to males. ${ }^{9}$ Our study did not show any significant results different in risk factors between genders.

Risk factors for STMI in our study were noted accordingly to other contemporary studies. Gautam et $\mathrm{al}^{6}$ in 2013 had presented following risk factors for CAD among 300 patients in Chitwan: smoking (50.8\%), diabetes (43.3\%), hypertension (36.8\%), previous CHD (31.5\%), dyslipidemia (26.3\%), family history of CHD (26.3\%) and obesity $(15.7 \%)$. Dubey et $\mathrm{al}^{3}$ has described risk factors in acute $\mathrm{MI}$ as smoking in $52(76.47 \%)$ Diabetes in 20 (29.41\%), systemic hypertension 41(60.29\%) and dyslipidemia in seven $(10.29 \%)$ cases. Adhikari ${ }^{10}$ had also described hypertension (65\%), smoking (57.8\%), dyslipidemia (45.5\%) and diabetes $(31.1 \%)$ as risk factors for ST Myocardial infarction.

Among the patients of below 40 years, all patients had smoked and $20 \%$ had positive family history of heart disease in first degree relatives. Tamrakar ${ }^{8}$ had described lower percentage of smoking $(64.3 \%)$, dyslipidemia $(9.6 \%)$ and family history $(9.6 \%)$ in study involving ST MI less than 45 years and higher percentage of diabetes (15.6\%) than our population. Single vessel disease and Left anterior descending artery were common in young MI as similar to Tamrakar. ${ }^{8}$

In age group $>60$ years, distribution of triple vessel disease was more. Such elderly age-related variation in number of vessels involved had been described by DeGare. ${ }^{11}$ It was described that during acute catheterization the elderly patients had more 3 -vessel disease, higher left ventricular (LV) enddiastolic pressure, lower LV ejection fraction, and higher initial rates of thrombolysis in Myocardial Infarction (TIMI) trial 2 or 3 flow. ${ }^{12}$

In young MI $<40$ years and elderly MI 60 years or more, LAD was the most infarct related artery. Primary PCI for anterior wall infarction was more common than for non-anterior wall myocardial infarction $(47.4 \%$ vs. $44.1 \%){ }^{4}$ However, Adhikari et $\mathrm{al}^{10}$ had described more inferior wall MI than anterior wall. The RCA as infarct related artery was found more in aged group 40 to 59 years in our study but statistically non-significant.

In STMI $\mathrm{Wu}^{12}$ had described chest pain in $87.3 \%$ epigastric pain in $6.9 \%$, cold sweating in $56.5 \%$, nausea or vomiting in $14.6 \%$, dyspnea in $34.2 \%$, back pain in $8.1 \%$, weakness in $9.6 \%$ and dizziness/ syncope in $17.3 \%$ cases. Presenting symptoms in our study were similar. Sweating was the second common symptom after chest pain. Presence of sweating in $90.95 \%$ of STMI and only $10.43 \%$ of NSTMI has been described and sweating with ACS symptoms predicted probability of STEMI (Likelihood ratio: 11.17 vs. 3.6 ). ${ }^{13}$ Gokhroo et al. ${ }^{13}$ had described firstly as sympathetic nervous system stimulation either as pain responsive or protective response to transient stunning induced hypotension and secondly as possibility of sympathetic cross connections between sweet glands and myocardial pain fibres, which have the same origin in thoracolumbar region.

Dyspnea had been present in $41 \%$ of patients which is much to the range eight to $22 \%$ in different literaturs. ${ }^{14,15}$ In our study, the dyspnea was unrelated to both age category, gender and number of vessels involved. The increase presenting symptom of dypnea in our study may be because of delay in presentations to the hospital and subsequent revascularization. Nausea and vomiting were common presenting symptoms in patients with either inferior or anterior wall AMI, but their frequency was unrelated to the infarct location. ( $69 \%$ vs. $56 \%$ and $33 \%$ vs. $26 \%$, respectively). 16 Dizziness had been presenting symptoms in $26.4 \%$ of patients with STMI which was higher than $17 \%$ of our patients. ${ }^{17}$ Epigastric pain had been described as in similar percentage as in our study. ${ }^{18}$

Limitations of the study: More varying parameters as symptoms and risk factors could have been added. We had collected data from the STMI patients who had undergone angioplasty and had excluded patients undergoing medical management. Most of the patients visiting our center could not afford the cost of PPCI even they had visited in the golden hours. Few of the patients get discharged on request or leave against medical advice to go to other center in Kathmandu. An extensive 
prospective study including all patients undergoing medical and interventional management is suggested.

\section{CONCLUSION}

Patients visiting CMSTH had classical symptoms and risk factors of myocardial infarction. Single vessel disease and Left anterior descending infarction was the most common vessel involved.

\section{ACKNOWLEDGEMENTS:}

We would like to acknowledge for the support of Dr. Tej Bhadhur Gurung, Dr Pradip Jung KC, Dr Madhu Gupta, Indra Dumre and the clinical nursing and emergency staffs of the hospital.

\section{REFERENCES}

1. Vaidya A, Pokharel P, Nagesh S, Karki P, Kumar S,Majhi S. Prevalence of coronary heart disease in the urban adult males of eastern Nepal: a population-based analytical cross sectional study. Indian Heart J.2009;61(4):341-7. PMID: 20635736.

2. Prajapati D, K.C. B, Ranabhat S. Acute Coronary syndrome. Annual report Shahid Gangalal National Heart Center.2015.

3. Dubey L, Bhattacharya R, Guruprasad S, Subramanyam G. Early clinical outcomes of primary percutaneous coronary intervention in Bharatpur, Nepal. MEDICA. 2013;8(2):103 $-7$.

4. O'Gara PT, Kushner FG, Ascheim DD, Casey DE, Jr. Chung MK, de Lemos JA, et al. ACCF/AHA guideline for the management of ST-elevation myocardial infarction: executive summary: a report of the American College of Cardiology Foundation/ American Heart Association Task Force on Practice Guidelines. J Am Coll Cardiol. 2013;61 (4):485-510. https://doi.org/10.1016/j.jacc.2012.11.019. PMID: 23256913.

5. Paudel B, Paudel K, Paudel R, Shrestha G, Maskey A, Panta B. A study of acute coronary syndrome in western region of Nepal. J Gandaki Med Coll Np. 2008;1:32-8.

6. Gautam M, Sogunuru G, Subramanyam G, Thapa L, Poudel R, Ghimire M, et al. Acute coronary syndrome in an intensive care unit of a tertiary care center: the spectrum and coronary risk factors.J Nepal Med Assoc.2013;52 (190):316-21. PMID: 24362653.

7. Simkhada R. Correlations of severity of ST segment elevation with respect to the site of right coronary artery lesions. J Nepal Med Assoc.2013;52(191):453-6. PMID: 24907949

8. Tamrakar R. Bhatt Y, Kansakar S, Bhattarai M, Shaha K, Tuladhar E. Acute myocardial infarction in young adults: study if risk factors, angiographic features and clinical outcomes. Nepalese Heart Journal. 2013;10:12-6.

9. Trigo J, Mimoso J, Gago P, Marques N, Faria R, Santos W, et al. Female gender: an independent factor in ST-elevation myocardial infarction. Rev Port Cardiol. 2010;29(9):138394. PMID: 21179979.

10. Adhikari CM, Prajapati D, Baniya B, Regmi S, Bogati A, Thapaliya S. Prevalence of Conventional Risk Factors in ST Segment Elevation Myocardial Infarction Patients in Shahid Gangalal National Heart Centre, Nepal. J Nepal Med Assoc. 2014.;52:914-19. PMID: 26982666.
11. DeGeare VS, Stone GW, Grines L, Brodie BR, Cox DA, Garcia E, et al. Angiographic and clinical characteristics associated with increased in-hospital mortality in elderly patients with acute myocardial infarction undergoing percutaneous intervention (a pooled analysis of the primary angioplasty in myocardial infarction trials). J Am Coll Cardiol. 2000;86(1):30-4. https:// doi.org/10.1016/S0002-9149(00)00824-9.

12. Wu Y, Wang P, Hsiao C, Chen I. Risk factors of acute ST segment elevation myocardial infarction patients without chest pain. Hong Kong j. emerg. Med.2012;19:98-102. https://doi.org/10.1177/102490791201900204.

13. Gokhroo RK, Ranwa BL, Kishor K, Priti K, Ananthraj A, Gupta S, et al. Sweating: A Specific Predictor of STSegment Elevation Myocardial Infarction Among the Symptoms of Acute Coronary Syndrome: Sweating In Myocardial Infarction (SWIMI) Study Group. Clin cardiol. 2016;39(2):90-5. https://doi.org/10.1002/clc.22498. PMID: 26695479.

14. Botker MT, Stengaard C, Andersen MS, Sondergaard HM, Dodt KK, Niemann T, et al. Dyspnea, a high-risk symptom in patients suspected of myocardial infarction in the ambulance? A population-based follow-up study. Scand J trauma resusc emerg med. 2016;24:15. https:// doi.org/10.1186/s13049-016-0204-9. PMID: 26872739.

15. Paudel R, Beridze N, Aronow WS, Ahn C, Sanaani A, Agarwal $\mathrm{P}$, et al. Association of chest pain versus dyspnea as presenting symptom for coronary angiography with demographics, coronary anatomy, and 2-year mortality. Arch Medical Sci. 2016;12(4):742-6. https:// doi.org/10.5114/aoms.2016.60959. PMID: 27478454.

16. Fuller EE, Alemu R, Harper JF, Feldman M. Relation of nausea and vomiting in acute myocardial infarction to location of the infarct. Am J Cardiol. 2009;104(12):163840. https://doi.org/10.1016/j.amjcard.2009.07.038. PMID: 19962467.

17. Kirchberger I, Meisinger C, Heier M, Kling B, Wende R, Greschik C, et al. Patient-reported symptoms in acute myocardial infarction: differences related to ST-segment elevation. J Intern Med. 2011;270(1):58-64. https:// doi.org/10.1111/j.1365-2796.2011.02365.x. PMID 21338424

18. Chowta KN, Prijith PD, Chowta MN. Modes of presentations of acute myocardial infarction. Indian J Crit Care Med.2005;9:151-4. https://doi.org/10.4103/09725229.19681. 